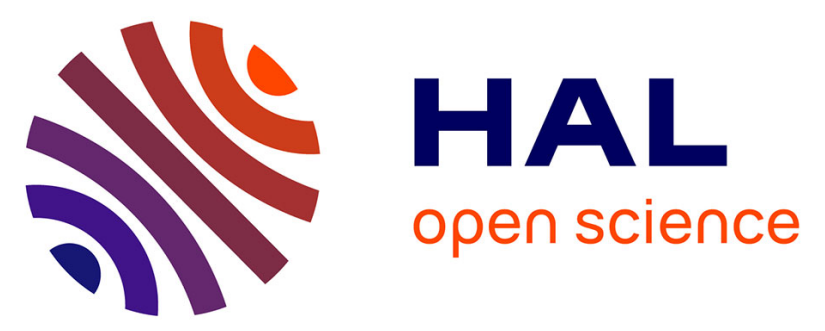

\title{
TSC22D1 and PSAP predict clinical outcome of tamoxifen treatment in patients with recurrent breast cancer
}

\author{
Danielle Meijer, Maurice P. H. M. Jansen, Maxime P. Look, Kirsten \\ Ruigrok-Ritstier, Iris L. Staveren, Anieta M. Sieuwerts, Ton Agthoven, John \\ A. Foekens, Lambert C. J. Dorssers, Els M. J. J. Berns
}

\section{To cite this version:}

Danielle Meijer, Maurice P. H. M. Jansen, Maxime P. Look, Kirsten Ruigrok-Ritstier, Iris L. Staveren, et al.. TSC22D1 and PSAP predict clinical outcome of tamoxifen treatment in patients with recurrent breast cancer. Breast Cancer Research and Treatment, 2008, 113 (2), pp.253-260. 10.1007/s10549008-9934-3 . hal-00478315

\section{HAL Id: hal-00478315 https://hal.science/hal-00478315}

Submitted on 30 Apr 2010

HAL is a multi-disciplinary open access archive for the deposit and dissemination of scientific research documents, whether they are published or not. The documents may come from teaching and research institutions in France or abroad, or from public or private research centers.
L'archive ouverte pluridisciplinaire HAL, est destinée au dépôt et à la diffusion de documents scientifiques de niveau recherche, publiés ou non, émanant des établissements d'enseignement et de recherche français ou étrangers, des laboratoires publics ou privés. 


\title{
TSC22D1 and PSAP predict clinical outcome of tamoxifen treatment in patients with recurrent breast cancer
}

\author{
Danielle Meijer - Maurice P. H. M. Jansen · Maxime P. Look • \\ Kirsten Ruigrok-Ritstier · Iris L. van Staveren - Anieta M. Sieuwerts • \\ Ton van Agthoven · John A. Foekens · Lambert C. J. Dorssers • \\ Els M. J. J. Berns
}

Received: 31 January 2008/ Accepted: 1 February 2008/Published online: 26 February 2008

(C) Springer Science+Business Media, LLC. 2008

\begin{abstract}
Purpose Two genes, TSC22 domain family, member 1 (TSC22D1) and prosaposin (PSAP) were identified in an in vitro functional screen for genes having a causative role in tamoxifen resistance. These genes were also present in our previously established 81-gene signature for resistance to first-line tamoxifen therapy. The aim of this study was to investigate the predictive value of these genes for tamoxifen therapy failure in patients with recurrent breast cancer. Experimental Design The mRNA levels of TSC22D1 and PSAP were analyzed by quantitative real-time polymerase chain reaction (qRT-PCR) in 223 estrogen receptor-positive primary breast tumors of patients with recurrent disease treated with first-line tamoxifen therapy. The main objective of this study was the length of progression-free survival (PFS). Results High mRNA levels of TSC22D1 and PSAP were significantly associated with shorter PFS and both were independent of the traditional predictive factors $(\mathrm{HR}=1.30,95 \% \mathrm{CI}=$ 1.04-1.64 $P=0.023$; and $\mathrm{HR}=1.40,95 \% \mathrm{CI}=1.03-$ $1.88, P=0.029$, respectively). In multivariate analysis, patients with high mRNA levels of both genes associated significantly with no clinical benefit $(\mathrm{OR}=0.19,95 \%$
\end{abstract}

Danielle Meijer and Maurice P.H.M. Jansen contributed equally to this work.

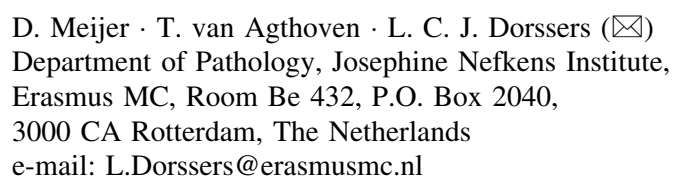

D. Meijer · T. van Agthoven · L. C. J. Dorssers ( $\square)$ Department of Pathology, Josephine Nefkens Institute, Erasmus MC, Room Be 432, P.O. Box 2040, 3000 CA Rotterdam, The Netherlands e-mail: L.Dorssers@erasmusmc.nl

M. P. H. M. Jansen · M. P. Look · K. Ruigrok-Ritstier · I. L. van Staveren - A. M. Sieuwerts - J. A. Foekens . E. M. J. J. Berns Department of Medical Oncology, Josephine Nefkens Institute, Erasmus MC, Rotterdam, The Netherlands
$\mathrm{CI}=0.06-0.62, P=0.006)$ and had the shortest PFS $(\mathrm{HR}=2.05,95 \% \mathrm{CI}=1.29-3.25, P=0.002)$. Conclusion These results confirm our previous in vitro and tumorrelated findings and are indicative for the failure of tamoxifen treatment in breast-cancer patients. Both TSC22D1 and PSAP are associated with clinical outcome and may have a functional role in therapy resistance.

Keywords TSC22D1 - PSAP - Tamoxifen · Breast cancer $\cdot$ Real-time PCR

\section{Introduction}

Breast cancer is the most common malignancy among women in the Western world. For more than 30 years, the antiestrogen tamoxifen has been used for the treatment of estrogen receptor (ER)-positive breast cancer. However, only half of the patients who have ER-positive tumors respond to tamoxifen therapy, while the other half show intrinsic resistance. Moreover, patients who initially respond to therapy, will ultimately acquire resistance during long-term treatment.

In the last decades, various studies have been performed to identify biological factors that predict the success of tamoxifen treatment [1]. Several molecular signatures have been reported to associate with tamoxifen therapy efficacy. A 21-gene [2] and a 2-gene signature, HOXB13/IL17BR [3], were correlated with disease-free survival in patients treated with tamoxifen in the adjuvant setting. In a genome-wide microarray study, we defined an 81-gene signature for tamoxifen therapy failure in patients with advanced disease [4]. Although these gene signatures classify for prediction of clinical outcome, they do not necessarily identify those genes that are functionally responsible for treatment resistance. 
Therefore, we performed a different approach, namely retroviral transduction of cDNA libraries, to identify genes causing tamoxifen resistance. In this in vitro functional screen, a set of 73 different genes has been identified. Using stringent selection criteria 7 genes have been reported to cause tamoxifen resistance [5]. The latter included epidermal growth factor receptor (EGFR), Neuregulin 1 (NRG1), platelet-derived growth factor receptor- $\alpha$ (PDGFRA), platelet-derived growth factor receptor- $\beta$ (PDGFRB), colony-stimulating factor 1 receptor (CSF1R), fibroblast growth factor 17 (FGF17), and breast cancer anti-estrogen resistance 4 (BCAR4). From these, EGFR, BCAR4, and NRG1 have already been related with tamoxifen resistance. High levels of EGFR and BCAR4 promote anti-estrogen resistant proliferation of breastcancer cells in vitro [5-7]. High expression levels of NRG1 changed MCF-7 breast cancer cells into an estrogen-independent and antiestrogen-resistant state, which was later mimicked in a transgenic mice model [8]. In addition, HER2 an established marker and a proven target for patients resistant to tamoxifen therapy, was amongst the remaining 66 discovered genes. However, the remaining genes need further validation to establish their role in resistance in vitro and their association with therapy failure in clinical breast cancer.

We propose that those genes identified with two independent approaches are interesting candidates as predictive markers and/or targets for treatment. Interestingly, only two genes, TSC22D1 (OMIM 607715; 13q14) and PSAP (OMIM 176801; 10q21-q22), were identified that were both highly expressed in tumors resistant to tamoxifen in our microarray study and were recovered from our functional screen.

In the current study, we investigated the clinical relevance of the TSC22D1 and PSAP in tamoxifen resistance with a third platform. To this end, gene mRNA levels were measured by qRT-PCR in 223 ER-positive primary breast tumors from patients who developed recurrent disease that was treated with tamoxifen as first-line therapy.

\section{Patients and methods}

\section{Patients}

This retrospective study has been approved by the medical ethics committee of the Erasmus MC Rotterdam, The Netherlands (MEC 02.953). Total RNA was isolated from frozen primary breast tumors of women who entered the clinic between 1981 and 1995 and from whom detailed clinical follow-up information was available $[9,10]$. The present study, in which coded tumor tissues were used, was performed in accordance with the Code of Conduct of the
Federation of Medical Scientific Societies in the Netherlands (http://www.fmwv.nl). Specimens were excluded when patients had received (neo)adjuvant hormonal therapy, when there was insufficient frozen tumor material, less than $30 \%$ epithelial tumor cells, poor RNA quality, or missing values for TSC22D1 or PSAP mRNA expression levels. In total, ER-positive breast tumors of 223 patients who developed advanced disease treated with first-line tamoxifen therapy were included in this study. ER and progesterone receptor $(\mathrm{PgR})$ protein status of the tumors was determined by routine ligand-binding assays or enzyme immunoassays. Eighty-five patients (38\%) underwent breast conserving lumpectomy and 138 patients (62\%) modified mastectomy. Ninety-two percent of the patients underwent an axillary-node dissection $(n=206)$ and 110 patients were node positive (49\%) at the time of surgical removal of the primary tumor.

All patients, including 13 patients with a local recurrence, were treated with first-line tamoxifen therapy (40 mg daily) for advanced disease. Adjuvant radiotherapy was given to $58 \%$ of the patients and 34 patients (15\%) were treated with adjuvant chemotherapy (16 patients anthracyclin-based (FAC/FEC) and 18 patients non-anthracyclin-based (CMF)). Median time to recurrence was 26 months. Median follow-up for recurrent disease of patients alive and treated with tamoxifen was 44 months. The median age of the patients at the time of primary surgery was 59 years (range, 26-89 years) and at the start of first-line tamoxifen therapy for recurrent disease 62 years (range, 29-90 years). In total, 168 patients were postmenopausal at start of therapy. Twenty-five patients had metastasis at diagnosis or developed distant metastasis (including supraclavicular lymph node metastasis) within 1 month after primary surgery.

The type of response to tamoxifen therapy was recorded as defined by standard Union Internationale Contre Cancer criteria [11]. No clinical benefit occurred in 91 patients (41\%) of whom 81 patients had progressive disease and 10 patients showed stable disease shorter than 6 months. One hundred thirty-two patients (59\%) showed clinical benefit from first-line tamoxifen therapy, of whom 11 patients showed a complete remission, 34 patients showed partial remission, and 87 patients showed stable disease longer than 6 months.

\section{RNA isolation and quantitative RT-PCR}

Tissue processing, RNA isolation, cDNA synthesis and quantitative real-time reverse-transcriptase polymerase chain reaction were performed as described previously [9]. The qRT-PCRs were performed on an ABI Prism 7700 Sequence Detection System (Applied Biosystems, 
Nieuwerkerk a/d IJssel, The Netherlands), according to the recommended protocol. Commercially available Assay-onDemand kits (Applied Biosystems) were used for TSC22D1 (Hs00394659_m1) and PSAP (Hs00358165_m1). Forty rounds of amplification were performed according to the supplier's protocol and at the end of the amplification fluorescent signals of the Taqman probes were used to generate Cycle threshold $(\mathrm{Ct})$ values from which mRNA expression levels were calculated. Expression levels of TSC22D1 and PSAP were normalized against average expression levels of three housekeeping genes, i.e., porphobilinogen deaminase (PBGD), hypoxanthine-guanine phospho-ribosyltransferase (HPRT) and $\beta$-2-microglobulin (B2M) [9].

Data analysis and statistics

Differences in mRNA levels were assessed with the MannWhitney $U$ test or Kruskal-Wallis test when appropriate. In these tests, patient and tumor characteristics were used as grouping variables. Associations between continuous variables were tested with the Spearman rank correlation $\left(\mathrm{R}_{\mathrm{s}}\right)$. Cox proportional-hazards models were applied to compute the hazard ratio (HR), which correlates expression levels of the variables with progression-free survival. Progression-free survival was defined as the time between start of treatment with tamoxifen as first-line systemic therapy for recurrent disease and the occurrence of disease progression. In multivariate analysis, Cox regression analysis was applied to determine whether TSC22D1 and PSAP had a predictive value and was independent when added to the base model of the traditional predictive factors age, menopausal status, disease-free interval (DFI), dominant site of relapse (DSR), and $\log$ ER and $\log$ PgR mRNA levels [12]. The proportional hazards assumption was not violated for TSC22D1 and PSAP in any of these analyses. Logistic-regression analysis was performed to calculate the odds ratio (OR) that defines the relation between expression levels and clinical benefit of tamoxifen therapy. Both HR and OR were calculated on log-transformed variables and were represented with their $95 \%$ confidence interval (95\% CI).

Only when the test for trend of a continuous variable was statistically significant a search for a cutoff point was considered justified. To define cutoff points, we used isotonic regression analysis to find the points where the monotonic relationship between the measured level and the hazard rate showed a distinct change. On the basis of these cutoff points, survival curves were generated using the method of Kaplan and Meier and a log-rank test was used to test for differences. Computations were performed with the STATA statistical package, release 10 (STATA Corp.,
College Station, TX). All P-values were two-sided and $P<0.05$ was considered statistically significant.

\section{Results}

Associations of TSC22D1 and PSAP with clinicopathological factors

In this study, TSC22D1 and PSAP mRNA expression levels were measured in 223 primary breast tumors using qRTPCR. Median expression levels of TSC22D1 and PSAP, their interquartile range, and their association with patient and tumor characteristics are shown in Table 1. TSC22D1 and PSAP expression levels did not have a relationship with menopausal status, tumor size, nodal status, tumor grade, nor with histological subtype (Table 1). All tissues were ER positive at the protein level and in agreement none of the samples tested negative for ER- $\alpha$ mRNA levels [9]. Both TSC22D1 and PSAP mRNA levels had an inverse correlation with ER and PgR at mRNA levels (Rs $=-0.06$ and -0.16 for TSC22D1 and Rs $=-0.03$ and -0.09 for PSAP, respectively). At protein levels of $\mathrm{ER}$ and $\mathrm{PgR}$, these inverse correlations were significant $(\mathrm{Rs}=-0.16$ and -0.26 for TSC22D1 and Rs $=-0.15$ and -0.17 for PSAP, respectively). Moreover, at mRNA levels TSC22D1 was significantly $(P<0.001)$ correlated with PSAP $\left(\mathrm{R}_{\mathrm{s}}=\right.$ $0.33)$, EGFR $\left(\mathrm{R}_{\mathrm{s}}=0.37\right)$, and ERBB2 $\left(\mathrm{R}_{\mathrm{s}}=0.24\right)$. Finally, PSAP had a significant $(P<0.001)$ correlation with EGFR $\left(\mathrm{R}_{\mathrm{s}}=0.22\right)$, but not with ERBB2.

Association of TSC22D1 and PSAP expression levels with progression-free survival and clinical benefit

Clinical endpoint of this study was progression after start of first-line tamoxifen therapy. TSC22D1 and PSAP mRNA levels, as univariate continuous log-transformed variables, were significantly associated with shorter PFS (HR $=1.39$, 95\% $\mathrm{CI}=1.12-1.72, P=0.003$ and $\mathrm{HR}=1.51,95 \%$ $\mathrm{CI}=1.13-2.02, \quad P=0.006, \quad$ respectively) $\quad($ Table 2$)$. TSC22D1 expression was also significantly associated with clinical benefit to tamoxifen therapy (OR $=0.64,95 \%$ $\mathrm{CI}=0.42-0.98, P=0.042$ ), while PSAP was not.

The significant findings of TSC22D1 and PSAP for PFS as continuous variable in univariate analysis justified the search for predictive cutoff points. Cutoff points for TSC22D1 and PSAP were 0.042 and 0.378 , respectively. Patient groups with the highest levels of TSC22D1 or PSAP had a worse outcome for first-line tamoxifen treatment $\quad(\mathrm{HR}=1.72, \quad 95 \% \quad \mathrm{CI}=1.26-2.33, \quad P<0.001$; $\mathrm{HR}=1.79,95 \% \quad \mathrm{CI}=1.23-2.59, \quad P=0.002$, respectively) (Table 2). The predictive values of dichotomized 
Table 1 Associations of TSC22D1 and PSAP mRNA levels with clinicopathological factors

\begin{tabular}{|c|c|c|c|c|c|c|c|c|}
\hline & \multirow[t]{2}{*}{ No. patients } & \multirow[t]{2}{*}{$\%$} & \multicolumn{3}{|c|}{ TSC22D1 } & \multicolumn{3}{|l|}{ PSAP } \\
\hline & & & Median & $\Delta^{\mathrm{a}}$ & $P^{*}$ & Median & $\Delta^{\mathrm{a}}$ & $P^{*}$ \\
\hline Age $(\text { years })^{\mathrm{b}}$ & & & & & $0.033^{\mathrm{c}}$ & & & $0.215^{\mathrm{c}}$ \\
\hline$\leq 40$ & 23 & 10 & 0.074 & 0.048 & & 0.624 & 0.357 & \\
\hline $41-55$ & 74 & 33 & 0.061 & 0.056 & & 0.668 & 0.611 & \\
\hline $56-70$ & 82 & 37 & 0.063 & 0.068 & & 0.711 & 0.607 & \\
\hline$>70$ & 44 & 20 & 0.046 & 0.059 & & 0.784 & 0.581 & \\
\hline Menopausal status ${ }^{\mathrm{b}}$ & & & & & $0.319^{\mathrm{d}}$ & & & $0.670^{\mathrm{d}}$ \\
\hline Premenopausal & 73 & 33 & 0.069 & 0.047 & & 0.648 & 0.592 & \\
\hline Postmenopausal & 150 & 67 & 0.060 & 0.068 & & 0.741 & 0.565 & \\
\hline Tumor size & & & & & $0.154^{\mathrm{e}}$ & & & $0.236^{\mathrm{e}}$ \\
\hline $\mathrm{PT} 1, \leq 2 \mathrm{~cm}$ & 63 & 28 & 0.061 & 0.058 & & 0.744 & 0.557 & \\
\hline $\mathrm{PT} 2,>2-5 \mathrm{~cm}$ & 130 & 58 & 0.066 & 0.061 & & 0.692 & 0.592 & \\
\hline PT $3,>5 \mathrm{~cm}+\mathrm{pT} 4$ & 30 & 13 & 0.049 & 0.059 & & 0.669 & 0.669 & \\
\hline Lymph nodes involved & & & & & $0.652^{\mathrm{e}}$ & & & $0.111^{\mathrm{e}}$ \\
\hline 0 & 98 & 47 & 0.062 & 0.068 & & 0.741 & 0.594 & \\
\hline $1-3$ & 52 & 25 & 0.061 & 0.056 & & 0.601 & 0.513 & \\
\hline$>3$ & 58 & 28 & 0.059 & 0.062 & & 0.693 & 0.557 & \\
\hline Grade & & & & & $0.912^{\mathrm{e}}$ & & & $0.763^{\mathrm{e}}$ \\
\hline Poor & 125 & 56 & 0.061 & 0.065 & & 0.704 & 0.664 & \\
\hline Unkown & 71 & 32 & 0.063 & 0.056 & & 0.728 & 0.568 & \\
\hline Good/moderate & 27 & 12 & 0.059 & 0.064 & & 0.652 & 0.338 & \\
\hline Histological type & & & & & $0.411^{\mathrm{e}}$ & & & $0.187^{\mathrm{e}}$ \\
\hline IDC & 134 & 60 & 0.061 & 0.065 & & 0.733 & 0.572 & \\
\hline ILC & 24 & 11 & 0.043 & 0.041 & & 0.654 & 0.371 & \\
\hline DCIS + IDC & 13 & 6 & 0.068 & 0.016 & & 0.637 & 0.580 & \\
\hline other/unknown & 52 & 23 & 0.068 & 0.063 & & & & \\
\hline PgR protein status ${ }^{\mathrm{f}}$ & & & & & $<0.001^{\mathrm{c}}$ & & & $0.010^{\mathrm{c}}$ \\
\hline PgR low & 37 & 17 & 0.089 & 0.094 & & 0.857 & 0.695 & \\
\hline PgR high & 183 & 83 & 0.059 & 0.052 & & 0.688 & 0.581 & \\
\hline Response tamoxifen first-line treatment & & & & & $0.021^{\mathrm{e}}$ & & & $0.268^{\mathrm{e}}$ \\
\hline Complete response & 11 & 5 & 0.037 & 0.034 & & 0.473 & 0.830 & \\
\hline Partial response & 34 & 15 & 0.045 & 0.073 & & 0.744 & 0.603 & \\
\hline Stable disease $>6$ months & 87 & 39 & 0.060 & 0.051 & & 0.649 & 0.521 & \\
\hline Stable disease $\leq 6$ months & 10 & 5 & 0.098 & 0.045 & & 0.919 & 0.673 & \\
\hline Progressive disease & 81 & 36 & 0.063 & 0.063 & & 0.758 & 0.532 & \\
\hline
\end{tabular}

a Interquartile range (q75-q25)

* Two-sided $P$-value

b At primary surgery

${ }^{c}$ Spearman rank correlation

d Mann-Whitney $U$ test

e Kruskal-Wallis test

${ }^{\mathrm{f}}$ In three samples PgR status was unknown

TSC22D1 and PSAP are visualized with Kaplan-Meier curves (Fig. 1). The differences in median PFS were 7.5 and 7 months between patients with high and patients with low expression levels of TSC22D1 or PSAP, respectively. Furthermore, TSC22D1 dichotomized at the cutoff point was also significantly associated with clinical benefit to tamoxifen therapy $(\mathrm{OR}=0.38,95 \% \mathrm{CI}=0.20-0.71$, $P=0.002$ ).

In multivariate analysis, both factors analyzed as continuous and dichotomized variable were significantly 
Table 2 Cox uni- and multivariate analysis for progression-free survival of patients receiving first-line tamoxifen therapy

\begin{tabular}{|c|c|c|c|c|c|c|c|c|c|c|}
\hline \multirow[t]{2}{*}{ Factor of base model } & \multirow[t]{2}{*}{ No. of patients } & \multirow[t]{2}{*}{$\%$} & \multicolumn{4}{|c|}{ Univariate analysis } & \multicolumn{4}{|c|}{ Multivariate analysis } \\
\hline & & & HR & \multicolumn{2}{|c|}{$95 \% \mathrm{CI}$} & $P$ & HR & \multicolumn{2}{|c|}{$95 \% \mathrm{CI}$} & $P$ \\
\hline$\leq 40$ & 14 & 6 & 1 & & & & 1 & & & \\
\hline $41-55$ & 69 & 31 & 0.74 & 0.41 & 1.32 & & 0.63 & 0.34 & 1.16 & \\
\hline $56-70$ & 81 & 36 & 0.65 & 0.37 & 1.16 & & 0.48 & 0.23 & 1.00 & \\
\hline$>70$ & 59 & 26 & 0.48 & 0.26 & 0.87 & & 0.35 & 0.16 & 0.75 & \\
\hline Menopausal status ${ }^{\mathrm{a}}$ & & & & & & 0.337 & & & & 0.112 \\
\hline Premenopausal & 55 & 25 & 1 & & & & 1 & & & \\
\hline Postmenopausal & 168 & 75 & 0.85 & 0.62 & 1.17 & & 1.47 & 0.91 & 2.36 & \\
\hline Disease-free-interval & & & & & & $<0.001$ & & & & $<0.001$ \\
\hline$\leq 1$ year & 60 & 27 & 1 & & & & 1 & & & \\
\hline $1-3$ years & 99 & 44 & 0.63 & 0.45 & 0.87 & & 0.58 & 0.42 & 0.82 & \\
\hline$>3$ years & 64 & 29 & 0.46 & 0.31 & 0.67 & & 0.44 & 0.30 & 0.65 & \\
\hline Dominant site of relapse & & & & & & 0.446 & & & & 0.550 \\
\hline Viscera & 84 & 38 & 1 & & & & 1 & & & \\
\hline Bone & 119 & 53 & 1.05 & 0.78 & 1.41 & & 0.91 & 0.66 & 1.24 & \\
\hline LRR & 20 & 9 & 0.76 & 0.45 & 1.29 & & 0.74 & 0.42 & 1.30 & \\
\hline ER- $\alpha$ mRNA level & 223 & 100 & 0.89 & 0.83 & 0.95 & $<0.001$ & 0.91 & 0.84 & 0.98 & 0.014 \\
\hline PgR mRNA level & 223 & 100 & 0.89 & 0.83 & 0.96 & 0.002 & 0.89 & 0.82 & 0.97 & 0.005 \\
\hline Factors analysed & & & & & & & Addit & to the & ase moc & \\
\hline \multicolumn{11}{|l|}{ TSC22D1 } \\
\hline Continuous variable & 223 & 100 & 1.39 & 1.12 & 1.72 & 0.003 & 1.30 & 1.04 & 1.64 & 0.023 \\
\hline \multicolumn{11}{|l|}{ Cutoff point for $\mathrm{PFS}^{\mathrm{b}}$} \\
\hline Low & 70 & 31 & 1 & & & & 1 & & & \\
\hline High & 153 & 69 & 1.72 & 1.26 & 2.33 & $<0.001$ & 1.60 & 1.16 & 2.19 & 0.004 \\
\hline \multicolumn{11}{|l|}{ PSAP } \\
\hline Continuous variable & 223 & 100 & 1.51 & 1.13 & 2.02 & 0.006 & 1.40 & 1.03 & 1.88 & 0.029 \\
\hline \multicolumn{11}{|l|}{ Cutoff point for $\mathrm{PFS}^{\mathrm{b}}$} \\
\hline Low & 41 & 18 & 1 & & & & 1 & & & \\
\hline High & 182 & 82 & 1.79 & 1.23 & 2.59 & 0.002 & 1.63 & 1.12 & 2.37 & 0.001 \\
\hline \multicolumn{11}{|l|}{ TSC22D1 \& PSAP } \\
\hline \multicolumn{11}{|l|}{ Cutoff point for $\mathrm{PFS}^{\mathrm{b}}$} \\
\hline Group 1 (both genes low) & 27 & 12 & 1 & & & & 1 & & & \\
\hline Group 2 (one gene low) & 57 & 26 & 1.54 & 0.93 & 2.54 & 0.09 & 1.49 & 0.9 & 2.47 & 0.12 \\
\hline Group 3 (both genes high) & 139 & 62 & 2.29 & 1.46 & 3.61 & $<0.001$ & 2.05 & 1.29 & 3.25 & 0.002 \\
\hline
\end{tabular}

${ }^{a}$ At start of first-line therapy for recurrent disease

${ }^{\mathrm{b}}$ Cutoff points were determined at 0.042 for TSC22D1 and 0.378 for PSAP

associated with PFS (Table 2), showing that they are independent from the traditional predictive factors (age, menopausal status, DSR, DFI, ER and PgR levels). When adjuvant chemotherapy was added to the base model, the estimates for TSC22D1 and PSAP did not change indicating that possible chemical castration prior to endocrine therapy has no significant impact on these results. In multivariate analysis for clinical benefit, dichotomized TSC22D1 levels showed a significant relation with clinical benefit $(\mathrm{OR}=0.39,95 \% \mathrm{CI}=0.19-0.78, P=0.008)$.
In a subsequent exploratory analysis, we divided our patient group into three subsets on the basis of their mRNA levels for both TSC22D1 and PSAP (both genes low (group 1), one gene low (group 2), and both genes high (group 3)). Compared with the patients having low mRNA levels for both genes (HR set at 1.0), those with high mRNA levels for both genes ( $62 \%$ of the patients) had a significantly shorter PFS $(\mathrm{HR}=2.29,95 \% \mathrm{CI}=1.46-3.61$, $P<0.001)$. Patients having low levels for one gene (26\% of the patients) showed an intermediate $\operatorname{HR}(1.54, P=0.09$, 

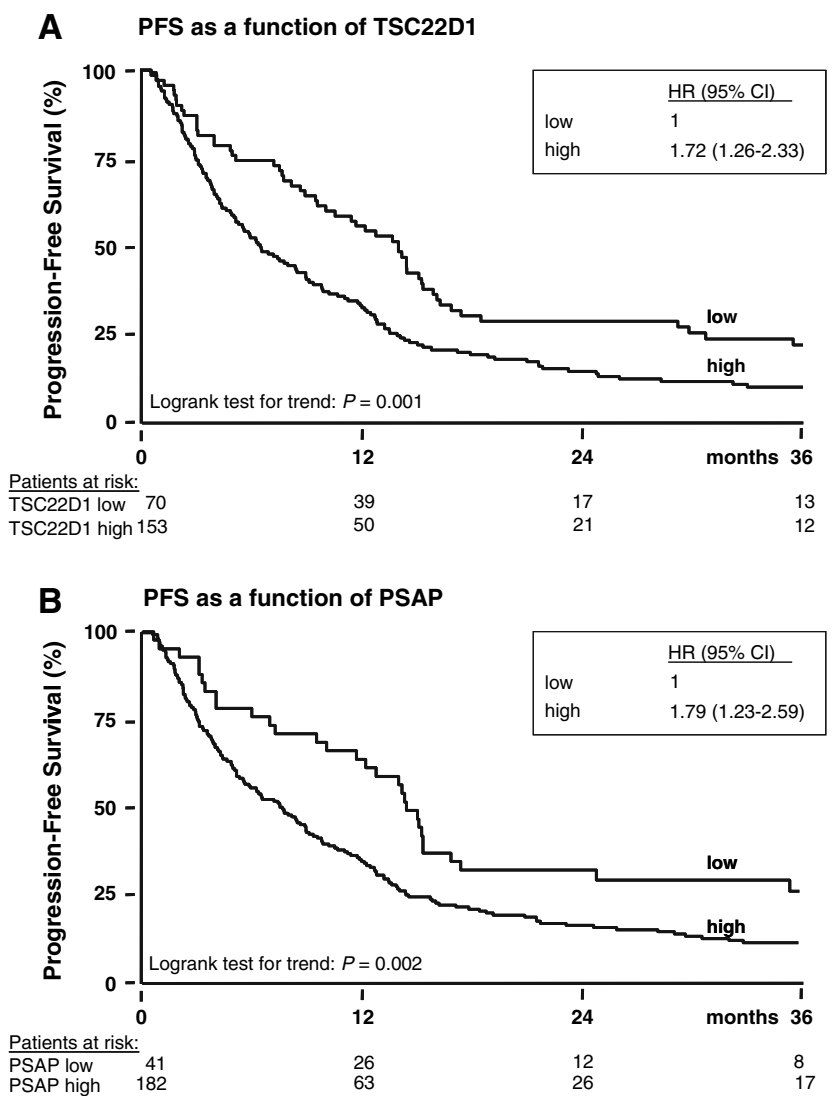

Fig. 1 Kaplan-Meier curves of progression-free survival for advanced breast cancer patients after start of first-line tamoxifen therapy as a function of TSC22D1 (a) and PSAP (b) mRNA levels. On the basis of cutpoint analyses, patients were divided into two groups, having low or high mRNA levels. Patients at risk are indicated

95\% CI $=0.93-2.54$ ) (Table 2). The difference in median PFS between patient groups having high versus low levels for both genes was 9 months (Fig. 2). Multivariate analysis for PFS (Table 2) and clinical benefit (OR intermediate $=0.30, \quad 95 \% \quad \mathrm{CI}=0.08-1.05, \quad P=0.06 ; \quad$ OR high $=0.19,95 \% \mathrm{CI}=0.06-0.62, P=0.006)$ showed that these results are independent from traditional predictive factors.

\section{Discussion}

Recently, we performed a genome wide screen in breast tumor samples to uncover a set of markers predictive for the type of response to endocrine therapy [4] and a functional screen using retroviral transduction of breast cancer cells for finding genes involved in tamoxifen resistance [5]. In the first approach, we have identified 81 genes predicting resistance to tamoxifen therapy and in the latter approach we found 73 candidate genes possibly having a causative role in tamoxifen resistance. Combining the results of both

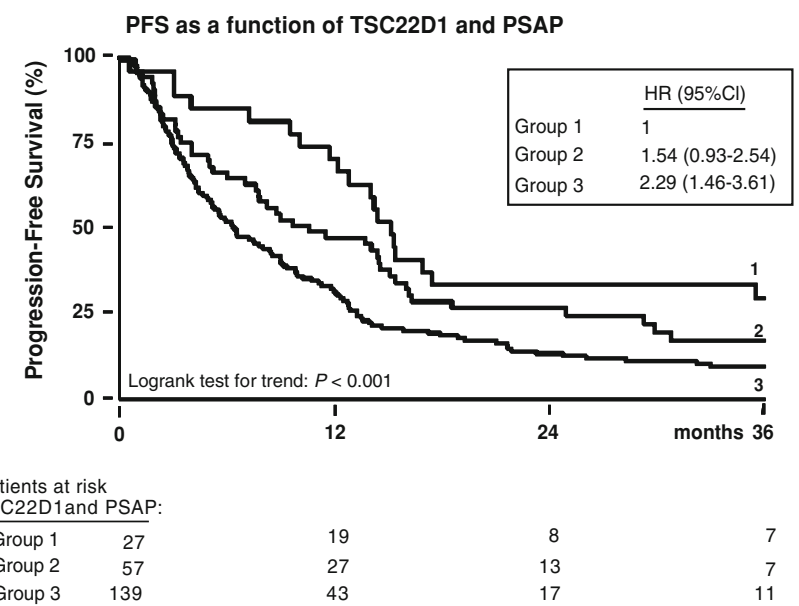

Fig. 2 Kaplan-Meier curve of progression-free survival for advanced breast cancer patients after start of first-line tamoxifen therapy as a function of combined TSC22D1 and PSAP mRNA levels. Patients were divided into three groups having low levels for both genes (group 1), low levels for TSC22D1 or PSAP (group 2), and high levels for both genes (group 3). Patients at risk are indicated

approaches, two overlapping genes, PSAP and TSC22D1, were identified.

In the current study, we used qRT-PCR as a third method to validate the predictive value of TSC22D1 and PSAP in tamoxifen therapy. The patient cohort in this study is clinically relevant because it included a large group of patients with stable disease. We investigated whether the expression levels of TSC22D1 and PSAP in primary breast tumors could predict the outcome of first-line tamoxifen treatment in patients with advanced disease. Our results confirm that patients having high mRNA levels of TSC22D1 and/or PSAP have a shorter PFS compared with patients having low levels of these genes.

TSC22D1 encodes a leucine-zipper transcription factor and belongs to the large family of early response genes. It was originally isolated as a Transforming Growth Factor, beta-1 (TGF $\beta)$ inducible gene in mouse osteoblasts [13]. TSC22D1 was proposed as a tumor-suppressor gene because it participates in growth inhibition of brain tumors, salivary-gland tumors and prostate cancers [14-16]. TSC22D1 was found to be downregulated in the presence of estrogens in MCF7 breast cancer cells [17], which was in concordance with our Spearman rank correlation data. Expression of the gene was shown to be upregulated through progesterone in growth-inhibited breast cancer cells [18].

With regard to TGF $\beta$ signaling it was shown that TSC22D1 enhanced TGF $\beta$ signaling in U973 cells by interaction with SMAD4 [19]. Furthermore, TSC22D1 increased levels of Cyclin-dependent Kinase Inhibitor 1A (CDKN1A, also known as p21 or CIP1), a downstream component of $\mathrm{TGF} \beta$, in colon carcinoma cells [20]. In 
addition, TGF $\beta$ is a well-known inhibitor of cell proliferation, which can be activated by the presence of tamoxifen [21]. These data support an inhibitory effect of TSC22D1 on tumor proliferation and seem to be in contrast with the fact that high levels of TSC22D1 are associated with tamoxifen resistance. However, it has been described that TGF $\beta$ can turn into a promoter of progression in later tumor stages and can stimulate tumor angiogenesis, extracellular matrix degradation, inhibition of antitumor immune response, and epithelial-to-mesenchymal transition [22].

PSAP is a lysosomal precursor protein of the saposins A, $\mathrm{B}, \mathrm{C}$, and D. PSAP has been reported to be present in conditioned media from the ER negative MDA-MB-231 as well as the ER positive MCF-7 breast cancer cell lines and in SV40 transformed normal HBL100 breast cells. Besides that, it also exists uncleaved in many biological fluids, including human milk [23, 24]. Estrogens have been reported to stimulate PSAP production in MCF-7 cells. Moreover, PSAP interacts with procathepsin D in human breast cancer cells $[25,26]$, suggesting a role in tumor invasiveness and metastasis. Misasi et al. have demonstrated an anti-apoptotic effect of PSAP in neuronal as well as non-neuronal cells $[27,28]$. They have shown that PSAP activates Mitogen-activated Protein Kinase 1 and 3 (ERK-2 and -1) and spingosine kinase, and they propose a possible role in cell survival for the MAPK and PI3K-Akt pathways through which these genes exert their function. Interestingly, both pathways have previously been reported to be associated with tamoxifen resistance [29, 30]. The latter supports our observed association of high levels of PSAP with tamoxifen treatment failure.

Almost two-thirds of the patients show high expression levels of both PSAP and TSC22D1. This group has an even poorer treatment outcome. The relative high percentage of patients with high levels of both genes may be explained by CDKN1A. It has been reported that TSC22D1 increase CDKN1A levels. Besides its well-known tumor-suppressive effects, high levels of CDKN1A have also been reported to have an unfavorable effect in anticancer treatment [31]. In permanently growth-inhibited tumor cells, a state that bears resemblance to tamoxifen treatment, CDKN1A has been shown to induce genes having an anti-apoptotic or mitogenic activity, including PSAP [32, 33]. Furthermore, this indicates that upregulation of $\mathrm{CDKN} 1 \mathrm{~A}$ also supports the possible tumor-promoting capabilities of TSC22D1.

In the present study, qRT-PCR analysis of mRNA levels of TSC22D1 and PSAP in primary breast-cancer specimens validates our previous genome wide and in vitro findings of these genes being associated with tamoxifen resistance. Since the mechanisms of action of PSAP and TSC22D1 have not been well characterized, the biological processes involved in tamoxifen resistance remain to be elucidated.
As discussed above, several lines of evidence have been reported already. It would be intriguing though to unravel the precise role of these genes in resistance with respect to the clinical significance in breast cancer.

We showed an association of high expression levels for both genes with failure of tamoxifen treatment in patients with recurrent breast cancer. On the basis of our functional screen, both genes have a putative causative role in therapy resistance and this may give new perspectives on biological pathways containing new drugable targets for tamoxifen therapy.

Acknowledgements We acknowledge the contributions of Dr. Jozien Helleman, drs. Marion E. Meijer-van Gelder and Roya Sarwari. This research was supported, in part, by grants of the Association for International Cancer Research, the Susan G. Komen Breast Cancer Foundation, the Dutch Cancer Society, and the "Breedte-strategie" of the Erasmus MC.

\section{References}

1. Loi S, Piccart M, Sotiriou C (2007) The use of gene-expression profiling to better understand the clinical heterogeneity of estrogen receptor positive breast cancers and tamoxifen response. Crit Rev Oncol Hematol 61:187-194

2. Paik S, Shak S, Tang G, Kim C, Baker J, Cronin M, Baehner FL, Walker MG, Watson D, Park T, Hiller W, Fisher ER, Wickerham DL, Bryant J, Wolmark N (2004) A multigene assay to predict recurrence of tamoxifen-treated, node-negative breast cancer. $\mathrm{N}$ Engl J Med 351:2817-2826

3. Ma XJ, Wang Z, Ryan PD, Isakoff SJ, Barmettler A, Fuller A, Muir B, Mohapatra G, Salunga R, Tuggle JT, Tran Y, Tran D, Tassin A, Amon P, Wang W, Enright E, Stecker K, Estepa-Sabal E, Smith B, Younger J, Balis U, Michaelson J, Bhan A, Habin K, Baer TM, Brugge J, Haber DA, Erlander MG, Sgroi DC (2004) A two-gene expression ratio predicts clinical outcome in breast cancer patients treated with tamoxifen. Cancer Cell 5:607-616

4. Jansen MP, Foekens JA, van Staveren IL, Dirkzwager-Kiel MM, Ritstier K, Look MP, Meijer-van Gelder ME, Sieuwerts AM, Portengen H, Dorssers LC, Klijn JG, Berns EM (2005) Molecular classification of tamoxifen-resistant breast carcinomas by gene expression profiling. J Clin Oncol 23:732-740

5. Meijer D, van Agthoven T, Bosma PT, Nooter K, Dorssers LC (2006) Functional screen for genes responsible for tamoxifen resistance in human breast cancer cells. Mol Cancer Res 4:379_ 386

6. van Agthoven T, van Agthoven TL, Portengen H, Foekens JA, Dorssers LC (1992) Ectopic expression of epidermal growth factor receptors induces hormone independence in ZR-75-1 human breast cancer cells. Cancer Res 52:5082-5088

7. Nicholson S, Sainsbury JR, Halcrow P, Chambers P, Farndon JR, Harris AL (1989) Expression of epidermal growth factor receptors associated with lack of response to endocrine therapy in recurrent breast cancer. Lancet 1:182-185

8. Atlas E, Cardillo M, Mehmi I, Zahedkargaran H, Tang C, Lupu R (2003) Heregulin is sufficient for the promotion of tumorigenicity and metastasis of breast cancer cells in vivo. Mol Cancer Res $1: 165-175$

9. Sieuwerts AM, Meijer-van Gelder ME, Timmermans M, Trapman AM, Garcia RR, Arnold M, Goedheer AJ, Portengen H, Klijn JG, Foekens JA (2005) How ADAM-9 and ADAM-11 
differentially from estrogen receptor predict response to tamoxifen treatment in patients with recurrent breast cancer: a retrospective study. Clin Cancer Res 11:7311-7321

10. Martens JW, Nimmrich I, Koenig T, Look MP, Harbeck N, Model F, Kluth A, Bolt-de Vries J, Sieuwerts AM, Portengen H, Meijer-Van Gelder ME, Piepenbrock C, Olek A, Hofler H, Kiechle M, Klijn JG, Schmitt M, Maier S, Foekens JA (2005) Association of DNA methylation of phosphoserine aminotransferase with response to endocrine therapy in patients with recurrent breast cancer. Cancer Res 65:4101-4117

11. Hayward JL, Carbone PP, Heuson JC, Kumaoka S, Segaloff A, Rubens RD (1977) Assessment of response to therapy in advanced breast cancer: a project of the programme on clinical oncology of the international union against cancer, Geneva, Switzerland. Cancer 39:1289-1294

12. Meijer-van Gelder ME, Look MP, Peters HA, Schmitt M, Brunner N, Harbeck N, Klijn JG, Foekens JA (2004) Urokinasetype plasminogen activator system in breast cancer: association with tamoxifen therapy in recurrent disease. Cancer Res 64:4563-4568

13. Shibanuma M, Kuroki T, Nose K (1992) Isolation of a gene encoding a putative leucine zipper structure that is induced by transforming growth factor beta 1 and other growth factors. J Biol Chem 267:10219-10224

14. Shostak KO, Dmitrenko VV, Garifulin OM, Rozumenko VD, Khomenko OV, Zozulya YA, Zehetner G, Kavsan VM (2003) Downregulation of putative tumor suppressor gene TSC-22 in human brain tumors. J Surg Oncol 82:57-64

15. Nakashiro K, Kawamata H, Hino S, Uchida D, Miwa Y, Hamano H, Omotehara F, Yoshida H, Sato M (1998) Down-regulation of TSC-22 (transforming growth factor beta-stimulated clone 22) markedly enhances the growth of a human salivary gland cancer cell line in vitro and in vivo. Cancer Res 58:549-555

16. Rentsch CA, Cecchini MG, Schwaninger R, Germann M, Markwalder R, Heller M, van der Pluijm G, Thalmann GN, Wetterwald A (2006) Differential expression of TGFbeta-stimulated clone 22 in normal prostate and prostate cancer. Int J Cancer 118:899-906

17. Frasor J, Barnett DH, Danes JM, Hess R, Parlow AF, Katzenellenbogen BS (2003) Response-specific and ligand dosedependent modulation of estrogen receptor (ER) alpha activity by ERbeta in the uterus. Endocrinology 144:3159-3166

18. Kester HA, van der Leede BM, van der Saag PT, van der Burg B (1997) Novel progesterone target genes identified by an improved differential display technique suggest that progestin-induced growth inhibition of breast cancer cells coincides with enhancement of differentiation. J Biol Chem 272:16637-16643

19. Choi SJ, Moon JH, Ahn YW, Ahn JH, Kim DU, Han TH (2005) Tsc-22 enhances TGF-beta signaling by associating with Smad4 and induces erythroid cell differentiation. Mol Cell Biochem 271:23-28

20. Gupta RA, Sarraf P, Brockman JA, Shappell SB, Raftery LA, Willson TM, DuBois RN (2003) Peroxisome proliferatoractivated receptor gamma and transforming growth factor-beta pathways inhibit intestinal epithelial cell growth by regulating levels of TSC-22. J Biol Chem 278:7431-7438

21. Buck MB, Knabbe C (2006) TGF-beta signaling in breast cancer. Ann N Y Acad Sci 1089:119-126

22. Pardali K, Moustakas A (2007) Actions of TGF-beta as tumor suppressor and pro-metastatic factor in human cancer. Biochim Biophys Acta 1775:21-62

23. O'Brien JS, Kishimoto Y (1991). Saposin proteins: structure, function, and role in human lysosomal storage disorders. Faseb J 5:301-308

24. Kishimoto Y, Hiraiwa M, O’Brien JS (1992) Saposins: structure, function, distribution, and molecular genetics. J Lipid Res 33:1255-1267

25. Campana WM, O'Brien JS, Hiraiwa M, Patton S (1999) Secretion of prosaposin, a multifunctional protein, by breast cancer cells. Biochim Biophys Acta 1427:392-400

26. Laurent-Matha V, Lucas A, Huttler S, Sandhoff K, Garcia M, Rochefort H (2002) Procathepsin D interacts with prosaposin in cancer cells but its internalization is not mediated by LDL receptor-related protein. Exp Cell Res 277:210-219

27. Misasi R, Sorice M, Di Marzio L, Campana WM, Molinari S, Cifone MG, Pavan A, Pontieri GM, O'Brien JS (2001) Prosaposin treatment induces PC12 entry in the S phase of the cell cycle and prevents apoptosis: activation of ERKs and sphingosine kinase. Faseb J 15:467-474

28. Misasi R, Garofalo T, Di Marzio L, Mattei V, Gizzi C, Hiraiwa M, Pavan A, Grazia Cifone M, Sorice M (2004) Prosaposin: a new player in cell death prevention of U937 monocytic cells. Exp Cell Res 298:38-47

29. Riggins RB, Schrecengost RS, Guerrero MS, Bouton AH (2007) Pathways to tamoxifen resistance. Cancer Lett 256:1-24

30. Massarweh S, Schiff R (2007) Unraveling the mechanisms of endocrine resistance in breast cancer: new therapeutic opportunities. Clin Cancer Res 13:1950-1954

31. Gartel AL (2006) Is p21 an oncogene? Mol Cancer Ther 5:1385-1386

32. Chang BD, Swift ME, Shen M, Fang J, Broude EV, Roninson IB (2002) Molecular determinants of terminal growth arrest induced in tumor cells by a chemotherapeutic agent. Proc Natl Acad Sci USA 99:389-394

33. Chang BD, Watanabe K, Broude EV, Fang J, Poole JC, Kalinichenko TV, Roninson IB (2000) Effects of p21Waf1/Cip1/Sdi1 on cellular gene expression: implications for carcinogenesis, senescence, and age-related diseases. Proc Natl Acad Sci USA 97:4291-4296 